\title{
Comment on: "Moving from Patient Advocacy to Partnership: A Long and Bumpy Road"
}

\author{
Alain Braillon ${ }^{1}$
}

Published online: 10 April 2017

(C) Springer International Publishing Switzerland 2017

Wong-Rieger rightly pledged for a transition from patient advocacy to partnership but her theoretical framework with four schematically psychosocial personalities overlooked the reallife issues [1].

First, partnership is already present. Two thirds of patient advocacy organizations received industry funding [2]. Greater transparency by the addition of patient advocacy groups to the Open Payments program (Sunshine Act) would be a flawed compromise: disclosing conflicts cannot dissolve them. A charity should not be registered among patient organizations if it accepts external funding, as healthcare professionals for a task force should not. Could a spoon be long enough to soup with the biggest defrauder ever? [3]. Industry's first goal is and will always be to create value for its shareholders.

Second, believing decision makers, including government agencies, could look for partnership with genuinely "independent patient and citizen voices" must not overlook the fact that cost constraints or economic issues are major issues for them. Third, partnership cannot be one-sided. The ignorant who are "motivated by good intentions" can be so easily fooled. Patients' advocates must develop basic skills about medicine (e.g., public health, pharmacology, psychology, clinical trials methodology) but also about strategic planning and communication. AIDS activists developed such skills, better than many professionals, and produced new paradigms, which is why they succeeded [4].

This comment refers to the article available at doi:10.1007/s40271-017-0216-1.

Alain Braillon

braillon.lain@gmail.com

1 University Hospital, Avenue Laennec, 80000 Amiens, France
Sadly, major steps forward, as by AIDS activists, are too few and must not mask potential drawbacks. Public outcry can unduly preclude the use of safe alternatives [5]. The pink ribbon campaign for breast cancer screening used public fervor to transform a disease into a market-driven industry, which is deliberately flying in the face of the scientific evidence challenging the clinical benefit of screening [6].

Advocacy for patients is not a gift from heaven, it needs not only efforts but also wisdom.

\section{Compliance with Ethical Standards}

Funding No funding was received for the preparation of this comment.

Conflict of interest Alain Braillon has no conflict of interest directly relevant to the content of this comment.

\section{References}

1. Wong-Rieger D. Moving from patient advocacy to partnership: a long and bumpy road. Patient. 2017. doi:10.1007/s40271-0170216-1 (Epub ahead of print).

2. Rose SL, Highland J, Karafa MT, Joffe S. Patient advocacy organizations, industry funding, and conflicts of interest. JAMA Intern Med. 2017;177(3):344-50. doi:10.1001/jamainternmed. 2016.8443.

3. Braillon A. Drug industry is now biggest defrauder of US government. BMJ. 2012;344:d8219.

4. Cairney R. In back alleys near Vancouver's AIDS conference, the disease was gaining ground. CMAJ. 1996;155:1160-3.

5. Tracy EE, Bortoletto P. The role of social networks, medical-legal climate, and patient advocacy on surgical options: a new era. Obstet Gynecol. 2016;127(4):758-62.

6. AbiGhannam N, Chilek LA, Koh HE. Three pink decades: breast cancer coverage in magazine advertisements. Health Commun. 2017;2:1-7. doi:10.1080/10410236.2016.1278496 (Epub ahead of print). 